\title{
Incorporating Health Care, English Proficiency, Social Integration, and Career Planning in Orientation Programming for New International Students
}

\author{
Roger D. Wessel and Jennifer L. Reed
}

"The United States historically has been and continues to be a destination for students from throughout the world" (Hammer, 1992, p. 217). The number of international students studying in the United States steadily increased from 305,000 students in 1980 to 528,700 students in 2000 (College Enrollments by Racial and Ethnic Group, Selected Years, 2003). International students have unique needs as individuals and as a subgroup on campus. This article describes a model program for new international students that colleges and universities can use to create an orientation plan for new international students to help them adjust to life at the university and in the United States.

\section{Transitional Needs of International Students}

The needs of new international students are many, but can be generalized into four categories: health care, English proficiency, social adjustment, and career planning. When international students and their families come to the United States, one of the primary issues for them to handle is health care. "As the numbers, expectations, and needs of these students increase, so does the need for appropriate health care" (Ogbudimkpa, Creswell, Lambert, \& Kingston, 1988, p. 313). Factors facing international students about health care include payment, language, and transportation.

Ebbin and Blankenship (1988) demonstrated that international students at the University of Southern California had higher stress-related conditions such as anxiety, gastritis, headache, constipation, insomnia, depression, chest pain, abdominal pain, and peptic ulcer, than domestic students at the university. They found that "the medical care sought by foreign students is frequently for stress-related problems" (p. 312).

Mental health is another medical issue international students face as they study in the United States. Fouard (1991) stated that more effective counseling was needed for international students as their numbers on campus increased. Counselors of international students should learn as much as possible about the cultures, values, communication styles, and habits of thought of the students they seek to help in order to establish rapport, approach their problems with sensitivity, and respond in ways most likely to be constructive (Althen, 1991; Dillard \& Chisolm, 1983). For example, Althen (1991), a foreign-student adviser, stated that he learned to use different volume levels with his

\footnotetext{
Roger D. Wessel (rwessel@ bsu.edu) is the Assistant Vice President for Planning, Research, and Evaluation in the Division of Student Affairs and Enrollment Management at Ball State University. He is also an Assistant Professor of Higher Education in the Department of Educational Studies. Jennifer L. Reed (jlreed@mac.com) is an Enrollment Specialist at Indiana University-Purdue University, Indianapolis.
} 
voice in working with different nationals. He also learned when to speak directly or indirectly with students from various countries.

According to Martin and Hammer (1989), "Communication competence has been posited as integral to an individual's successful adaptation in an overseas environment" (p. 304). The root of many issues international students faced was English proficiency. Language competency, the ability to communicate ideas, is the medium by which two cultures can understand one another. Zimmerman (1995) stated, "International students must adapt or adjust to a sociocultural system which is different from their own. At the center of this adaptation process is communication" (p. 322). In a study of adaptation of international students to American universities, she found that

The most important factor in international students' adjustment to American culture was frequency of interaction with American students. . . . A willingness to seek out information by interacting with American students serves to aid international students in learning about American culture. . . Providing opportunities for them to talk with American students seems to be of greater use in assisting their adaptation. (p. 329-330)

Zimmerman recommended using current international students as peer counselors to assist incoming students in enhancing the channels on which international students already rely.

Correlated with English proficiency is social adjustment. In order to have a healthy college experience as an international student, a social support system is needed to establish and maintain social adjustment to the host country of study. Abe, Talbot, and Geelhoed (1998) stated that concerns of international students included learning English, homesickness, cultural differences, lack of significant relationships with others, and lack of opportunities to interact socially with American students. The authors, describing a semester-long International Peer Program implemented at a public university in the Midwest, emphasized the importance of the international student office, friends, professors, roommates, and involvement in student organizations. International students needed more opportunities to develop their English skills and more information about career services and counseling services. Students who participated in the peer program scored significantly higher on the social adjustment subscale than the control group, suggesting that the interactions of the peer group "enhanced the international students' interpersonal skills, which are crucial for success in the campus environment" (p. 545).

Barrat and Huba (1994) examined a number of variables believed to play a role in the adjustment of international undergraduate students at a large Midwestern state university. They found "communication variables (written and oral/aural) were consistently related to adjustment" (p. 431). They stated that "perceived English language skills were found to be significantly related to international students' perceived self-esteem at present" (p. 432). Students who felt competent in speaking with American students and comfortable developing relationships with them evaluated the people in the community positively. Olaniran (1993) stated both "close communication interactions and casual acquaintanceship interactions with host nationals showed significant strength 
toward reduction of cultural stress" (p. 81).

Vocational and career planning are important needs of international students. Leong and Sedlacek (1989) found that international students expressed greater overall academic and career needs than American students. International students placed greater emphasis on the academic and vocational aspects of a college education than on social and extracurricular aspects. The needs of international students were found to include "the need to learn how to prepare for the careers they were interested in, and the need to see a counselor about their career plans" (p. 109). International students were concerned about their academic plans, and they needed help from academic advisers in selecting and scheduling courses and in establishing their academic program plan.

The career needs of international students included United States employment, employment in the home country, interview barriers, interviewing techniques, and general career planning (Spencer-Rodgers, 2000). International students indicated the greatest need for work experience, followed by job-search skills, and finally, careerplanning activities. Spencer-Rogers claimed that international students needed "countryspecific, culturally sensitive career-planning services" (p. 34). She determined that

The results of this study suggest a lack of knowledge regarding American

employment opportunities and the U.S. job market, as well as a deficit of job-search skills among international students. A majority of the participants (87\%) expressed a moderate or strong need to prepare an American-style resume and to overcome language and cultural barriers in the American employment interview (76\% and $72 \%)$. (p. 43)

\section{New Student Orientation Programs}

Strumpf, Sharer, and Wawrzynski (2003) stated that The history of orientation programs in the United States is almost as old as higher education itself. Harvard faculty saw the value of establishing a support system early in a student's education and was the first institution to formalize a system by which experienced students assisted new students in their transition to the institution. ... In addition to a personalized support system, students also experienced certain rites of passage, which, in today's vernacular, might be considered hazing. Clearly this system was not without its flaws, but it was the beginning of the formalization of orientation as a process for supporting students in their transition to the higher education community. (p. 31)

Pascarella, Terenzini, and Wolfle (1986) viewed college orientation as a form of anticipatory socialization. Students who participated in precollege orientation programs were thought to be more successful in becoming initially integrated into an institution's academic and social system than students who did not participate in an orientation program. Benefits to higher integration led to "increased commitment to and lower likelihood of voluntary withdrawal from the institution” (p. 157).

Dannells and Wilson (2003) listed a 12-step practice-to-theory-to-practice model to apply appropriate theories to the orientation process. The steps started with identifying 
the problems and concerns which needed to be addressed and what outcomes were desired from the orientation program. Next, the practitioner examined and decided which theories would be useful in accomplishing these goals. The campus environment was analyzed to determine which theory best fit that environment. Sources of support and challenge were identified. Lastly, the program was designed, implemented, and evaluate. Strumpf et al. (2003) stated that

Orientation programs have evolved from their roots in individualized faculty attention to programs that attempt to address a multitude of important issues while meeting the needs of a diverse student population. Clearly, orientation programs will continue to grow and change as they meet future needs. (p. 31) Jacobs and Bowman (2003) stated that orientation programs had evolved such that professionals were observing and responding to the special needs found in diverse groups. Various subgroups of students were unique and had individual adjustment needs. Orientation directors should determine those needs and individualize orientation programming as much as possible. Support systems were built into the programs for nontraditional students. Orientation for nontraditional students included programs for the visually handicapped, transfer students, adult evening students, commuting students, student athletes, Alaskan Natives, ex-offenders, and programs for international students (Jacobs and Bowman, 2003; Jarmul, 1977; McCannon, 1975, McVey, 1977; Salisbury, 1971).

Pascarella et al. (1986) suggested extending orientation programs from the typical two- or three-day program to continue throughout the academic year. "Such an ongoing program might function to both extend and reinforce the impact of initial orientation experiences" (p. 172). For example, McCannon (1975) described an orientation program for adult evening students at Drake University that consisted of seven weekly meetings which lasted one and a half hours each.

Dillard and Chisolm (1983) stated that, "Unlike American students who first experience college life, many international students encounter tremendous culture shock once they enter the United States and engage in campus activities" (p. 101). Jacobs and Bowman (2003) believed that "orientation programs for international students should be distinct from those provided the general student population" (p. 87). They recommended that "admissions procedures, academic survival, immigration policies, social involvement, and community norms" (p. 87) should be covered in an orientation program for international students. Hammer (1992) stated that

advisers need to develop orientation programs that emphasize international students' active participation in their culture learning. Similarly, advisers need to focus on American students and the benefits that international students offer to them and to the university community at large. (p. 231)

\section{Method}

The purpose of this project was to design a model orientation program for new international students that colleges and universities could use to create an orientation 
plan for new international students as they adjusted to life at the institution and in the United States. This program addressed health care, English proficiency, social integration, and career planning needs of international students, as identified in the review of related literature. Concepts and models from traditional freshman, nontraditional, and international orientation programs were used in this design.

The program was designed to complement other new student activities before classes started (hereafter referred to as Welcome Week activities). The researchers obtained existing international student orientation programs from other institutions. These programs were thoroughly reviewed, seeking common programming themes that could form the basis for a model orientation program for international students.

\section{Introductory Orientation Program for International Students}

The orientation program for international students has two components. The first component consists of an introductory five-day program. The second component consists of an extended continuing program that addresses transitional needs throughout the semester.

The five-day orientation program begins on Wednesday and ends the Sunday before classes began on Monday (see figure 1). Orientation is cosponsored by the Center for International Education and the Office of Orientation. Participants include faculty with international backgrounds, returning international students, and American students who have traveled or studied abroad. Returning international students and American students who have traveled abroad participate as orientation leaders. Leaders develop friendships with new students, help them with their conversational English, and provide a sense of familiarity on campus. Leaders also participate in the continuing orientation sessions. The Office of Orientation trains the orientation leaders.

\section{FIGURE 1}

\section{Schedule for Introductory Orientation Program for International Students}

\section{Wednesday}

1:00-1:30 p.m.

1:30-2:30 p.m.

2:30-7:00 p.m.

7:00-9:00 p.m.
Welcome

Lunch in the village with orientation leaders

Move-in

Welcome dinner
Breakfast

Presentation: Tradition and history of the university

Presentation: Choosing your major

Campus tour

Student IDs

\section{Thursday}

$\begin{array}{ll}\text { 8:00-9:00 a.m. } & \text { Breakfast } \\ \text { 9:00-9:30 a.m. } & \text { Presentation: Tradition and history of the university } \\ \text { 9:30-10:00 a.m. } & \text { Presentation: Choosing your major } \\ \text { 10:00 -11:00 p.m. } & \text { Campus tour } \\ \text { 11:00-11:30 p.m. } & \text { Student IDs }\end{array}$


11:30 a.m. $-12: 30$ p.m.

12:30-3:00 p.m.

3:00-4:00 p.m.

4:00-7:00 p.m.

8:00 p.m.-12:00 a.m.

\section{Friday}

8:00-9:00 a.m.

9:00-11:00 a.m.

11:00 a.m.-12:00 p.m.

12:00-1:00 p.m.

1:00-1:50 p.m.

2:00-2:50 p.m.

3:00-3:50 p.m.

4:00-4:50 p.m.

5:00-6:00 p.m.

7:00 p.m.-12:00 a.m.

\section{Saturday}

11:00 a.m.-2:00 p.m. 8:00-10:00 p.m.

\section{Sunday}

2:00-4:00 p.m.

4:00-5:00 p.m.

5:00-6:30 p.m.

6:30-7:30 p.m.
Lunch

Placement tests

Trip to the bank

Trip to department store

Dinner and dance with the president of the university

Breakfast

Register for classes

Bookstore

Lunch

Health Center tour

Learning Center tour

Counseling Center tour

Career Center tour

Dinner

Welcome Week activities

Welcome Week activities

Presentation: Returning international students

Convocation

Immigration and visa session

Tour of city

Meet conversation partners

Day One: Wednesday. The program starts with a welcome session where international students meet staff from the Center for International Education and the orientation leaders. The leaders help students check into their new living arrangements. Most of the day is designed to help new students move in to their residence halls or apartments. Leaders and volunteers have lunch with new students in a shopping village adjacent to the university.

In the evening, new students and orientation leaders attend a welcome dinner. Participants include faculty and staff from the Center for International Education. The new international students are introduced to each other, to faculty and staff, and to the orientation leaders.

Day Two: Thursday. After breakfast with orientation leaders, students meet the Vice President for Student Affairs as (s)he gives a presentation about the tradition and history of the university. Then the students meet the Director of International Education. After the presentations, new students split into two groups of undergraduate students and 
graduate students. They are further divided into smaller groups of five students each. Each group has an assigned orientation leader. Between breakfast and lunch, the new students hear a presentation from academic advising on majors and the curriculum. Undergraduate students are advised by a freshman adviser, while graduate students meet with departmental advisers within their majors. Academic advisers help guide students in choosing a major, help them create a plan for graduation, and answer questions. Then the assigned orientation leaders take their groups to get their student IDs. Lunch is on campus.

The afternoon is designated for any placement tests new students may need. Later in the afternoon orientation leaders take their groups to a bank to open an account. Next, orientation leaders take their groups to a local department store to shop for groceries, supplies for school and their apartment or room, and other basic needs. Dinner is semi-formal with the president of the university, who provides an official welcome to the university. A dance follows the dinner.

Day Three: Friday. After breakfast, orientation leaders take their groups to register for classes. Leaders give tours of the campus and finish the tours at the university bookstore so students may purchase books and supplies. During tours, orientation leaders discuss safety tips and how to contact the police.

After lunch, students tour the health center, where they are given a presentation about health care and insurance in the United States. Touring the facility and meeting the doctors and nurses help the students feel more comfortable about using services at the health center.

The Learning Center (academic support services) provides services to help students with academic issues. Students tour this facility where they are given a presentation about available resources. The students then visit the Counseling Center and hear a presentation on services offered at the center. This visit helps students feel more comfortable about using their services. The students then go to a presentation by the Career Center where staff discuss career planning and inform students about the center's services.

After dinner, students participate in Welcome Week activities with orientation leaders and student volunteers. These activities give new international students a chance to meet and socialize with other students, thus helping them integrate into campus life.

Day Four: Saturday. New international students participate in Welcome Week activities throughout the day with their orientation leaders, student volunteers, and other new students. As the new international students participate in these events with other new students, they begin to feel a part of the university and experience the American culture. In the evening, the new international students participate in an informal session where current international students discuss available student services. During this presentation students learn from their peers about their initial experiences and how they adjusted to life in the United States. This session provides support for new students as they meet challenging experiences in the United States.

Day Five: Sunday. The day before classes start, the university president addresses all new students at a convocation. At this event, students get a sense of the academic 
tradition of the university and feel they are a part of the student body along with the new American freshman students.

A Sunday afternoon session addresses immigration, visas, and laws of the United States. After the session, students take a tour on a city bus to the mall, downtown area, and the cultural center. This tour can help students feel more comfortable in the community.

After the tour, new students are assigned and meet their conversation partners. Conversation partners are volunteers from campus and the community who spend time getting to know an international student and helping him or her with conversational English skills. They also help integrate new international students into the community.

\section{Continuing Orientation Program for International Students}

In the continuing orientation program, new international students are supported by other international students who are experiencing or have already experienced many of the same situations new students will face. This orientation program extends into the semester, helping students learn more about the campus, culture, and services offered in their new community. The continuing orientation program meets once a week to address issues and concerns of international students. The sessions consist of three parts: social time, support group meetings, and an informational presentation. During the social time, students interact and enjoy refreshments with other students. During the support time, students divide into their original orientation groups with their orientation leaders who facilitate a discussion. Students are encouraged to talk about the presentation or issues such as problems they faced during the week (such as homesickness) or something new they learned about the university or community.

During the informational presentation, a topic such as a student service or a concern relating to international students is addressed. Informational sessions include:

Session 1: Safety: Campus and Community (sponsored by University Police). University police officers give a presentation on safety in the community and on campus. They explain how to contact the police, fire department, and emergency medical service, and discuss self-defense classes available on campus.

Session 2: Study Skills (sponsored by the Learning Center). Staff members from the Learning Center address study skills such as how to prepare for tests, study groups, and available tutoring options.

Session 3: Academic Success at an American University (sponsored by the Learning Center). Topics covered include how to plan for academic success, time management, and the American educational system.

Session 4: Undergraduate and Graduate Student Life (sponsored by Housing and Residence Life and the Graduate School). Residence Life staff members talk with undergraduates about residence halls, student involvement, and time management. The Graduate School talks with graduate students about graduation requirements, library privileges of graduate students, and assistantships.

Session 5: Recreation Services (sponsored by the Office of Recreation Services). A 
representative from Recreation Services explains facilities, intramural sports, and programs available for students.

Session 6: Culture Shock (sponsored by the Center for International Education). Returning international students and faculty share their experiences with "culture shock" while in the United States.

Session 7: United States Health Care (sponsored by the Health Center). A representative from the Health Center explains health care in the United States and answers questions about health insurance, the Health Center, and the local hospital.

Session 8: Colloquial English (sponsored by the Department of English). Professors from the English department discuss American English phrases. This session is interactive and involves role playing.

Session 9: Designing an American Resume (sponsored by the Career Center). Career advisers help students learn how to create a resume in an American style.

Session 10: Family Issues (sponsored by the Center for International Education). This session is for students who came to the university with children and spouses. Topics such as American elementary school education and balancing work and family are discussed.

Session 11: Information about the local city (sponsored by the Center for International Education). Maps, travel guides, and tips for travel are presented. Students learn about cultural and sporting events, entertainment and dining, and other features of the city.

\section{Summary}

This model orientation program has been designed for new international students, using information that the literature has identified as being prominent in the lives of international students as they matriculate to American colleges and universities. The introductory and continuing orientation programs are designed to help integrate international students into the university and American culture, improve their conversational English skills, inform them about health care in the United States, help them with career development, and help them learn more about the services and facilities available to them. The purpose of this model is to provide orientation offices with a starting point that can be adapted as they develop an international student orientation program that is unique to their campus. 


\section{References}

Abe, J., Talbot, D. M., \& Geelhoed, R. J. (1998). Effects of a peer program on international student adjustment. Journal of College Student Development, 39, 539-547.

Althen, G. (1991). Some help and some myths. The Counseling Psychologist, 19, 62-65.

Barratt, M., \& Huba, M. (1994). Factors related to international undergraduate student adjustment in an American community. College Student Journal, 28, 422-435.

College enrollment by racial and ethnic group, selected years. (2003, August 29). The Chronicle of Higher Education: The Almanac, 2003-4, p. 15.

Dannells, M., \& Wilson, M. E. (2003). Theoretical perspectives on orientation. In J. A. Ward-Roof \& C. Hatch (Eds.), Designing successful transitions: A guide for orienting students to college (2nd ed., pp. 15-29, Monograph No. 13). Columbia, SC: National Resource Center for The First-Year Experience and Students in Transition (University of South Carolina).

Dillard, J., \& Chisolm, G. (1983). Counseling the international student in a multicultural context. Journal of College Student Personnel, 24, 101-105.

Ebbin, A., \& Blankenship, E. (1988). Stress-related diagnosis and barriers to health care among foreign students: Results of a survey. College Health, 36, 311-312.

Fouard, N. (1991). Training counselors to counsel international students: Are we ready? The Counseling Psychologist, 19, 66-71.

Hammer, M. (1992). Research, mission statements, and international student advising offices. International Journal of Intercultural Relations, 16, 217-236.

Jacobs, B., \& Bowman, B. S. (2003). Methods for orienting diverse populations. In J. A. Ward-Roof \& C. Hatch (Eds.), Designing successful transitions: A guide for orienting students to college (2nd ed., pp. 83-96, Monograph No. 13). Columbia, SC: National Resource Center for The First-Year Experience and Students in Transition (University of South Carolina).

Jarmul, L. (1977). College orientation for visually handicapped students: A summer program at Queensborough Community College. Education of the Visually Handicapped, 9, 56-60.

Leong, F., \& Sedlacek, W. (1989). Academic and career needs of international and United States college students. Journal of College Student Development, 30, 106-111.

Martin, J., \& Hammer, M. (1989). Measuring competence: Behavioral categories of intercultural communication competence: Everyday communicators' perceptions. International Journal of Intercultural Relations, 13, 303-332.

McCannon, R. (1975). Effectiveness of an orientation and counseling program for adult evening students at Drake University. St. Louis, MO: Paper presented at the Adult Education Research Conference. (ERIC Document Reproduction Service No. ED110842)

McVey, R. (1977). Establishing a college orientation program for ex-offenders. (ERIC Document Reproduction Service No. ED147677) 
Ogbudimkpa, J., Creswell, W., Lambert, B., \& Kingston, R. (1988). Health needs assessment of international students and their families at the University of Illinois. College Health, 36, 313-316.

Olaniran, B. (1993). International students' network patterns and cultural stress: What really counts. Communication Research Reports, 10, 69-83.

Pascarella, E., Terenzini, P., \& Wolfle, L. (1986). Orientation to college and freshman year persistence/withdrawal decisions. Journal of Higher Education, 57, 155-175.

Salisbury, L. (1971). College orientation program for Alaskan Natives COPANEducation for survival. Washington, DC: Office of Education (DHEW). (ERIC Document Reproduction Service No. ED182063)

Spencer-Rodgers, J. (2000). The vocational situation and country of orientation of international students. Journal of Multicultural Counseling and Development, $28,32-48$.

Strumpf, G., Sharer, G., \& Wawrzynski, M. (2003). 20 years of trends and issues in orientation programs. In J. A. Ward-Roof \& C. Hatch (Eds.), Designing successful transitions: A guide of orienting students to college (2nd ed., pp. 15-29, Monograph No. 13). Columbia, SC: National Resource Center for The First-Year Experience and Students in Transition (University of South Carolina).

Zimmerman, S. (1995). Perceptions of intercultural communication competence and international student adaptation to an American campus. Communication Education, $44,321-335$. 